\title{
Structural Design Optimization of a Tiltrotor Aircraft Composite Wing to Enhance Whirl Flutter Stability
}

Kim, Taeseong; Kim, Jaehoon; Shin, Sang Joon; Kom, Do-Hyung

Published in:

Composite Structures

Link to article, DOI:

10.1016/j.compstruct.2012.08.019

Publication date:

2013

Link back to DTU Orbit

Citation (APA):

Kim, T., Kim, J., Shin, S. J., \& Kom, D-H. (2013). Structural Design Optimization of a Tiltrotor Aircraft Composite Wing to Enhance Whirl Flutter Stability. Composite Structures, 95, 283-294.

https://doi.org/10.1016/j.compstruct.2012.08.019

\section{General rights}

Copyright and moral rights for the publications made accessible in the public portal are retained by the authors and/or other copyright owners and it is a condition of accessing publications that users recognise and abide by the legal requirements associated with these rights.

- Users may download and print one copy of any publication from the public portal for the purpose of private study or research.

- You may not further distribute the material or use it for any profit-making activity or commercial gain

- You may freely distribute the URL identifying the publication in the public portal 


\section{Accepted Manuscript}

Structural Design Optimization of a Tiltrotor Aircraft Composite Wing to Enhance Whirl Flutter Stability

Taeseong Kim, Jaehoon Lim, Sang Joon Shin, Do-Hyung Kim

PII: S0263-8223(12)00385-6

DOI: http://dx.doi.org/10.1016/j.compstruct.2012.08.019

Reference: COST 4759

To appear in:

Composite Structures

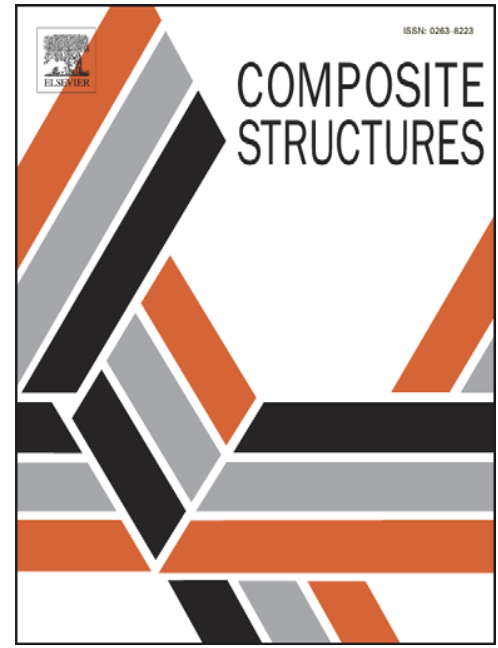

Please cite this article as: Kim, T., Lim, J., Shin, S.J., Kim, D-H., Structural Design Optimization of a Tiltrotor Aircraft Composite Wing to Enhance Whirl Flutter Stability, Composite Structures (2012), doi: http://dx.doi.org/ 10.1016/j.compstruct.2012.08.019

This is a PDF file of an unedited manuscript that has been accepted for publication. As a service to our customers we are providing this early version of the manuscript. The manuscript will undergo copyediting, typesetting, and review of the resulting proof before it is published in its final form. Please note that during the production process errors may be discovered which could affect the content, and all legal disclaimers that apply to the journal pertain. 


\title{
Structural Design Optimization of a Tiltrotor Aircraft Composite Wing to Enhance Whirl Flutter Stability
}

\author{
Taeseong Kim, ${ }^{1}$ \\ DTU Wind Energy, Ris $\phi$ campus, Roskilde, 4000, Denmark \\ Jaehoon Lim, ${ }^{2}$ SangJoon Shin, ${ }^{3}$ \\ Seoul National University, Seoul, Korea \\ and \\ Do-Hyung Kim ${ }^{4}$ \\ Korea Aerospace Research Institute, Daejeon, Korea
}

\begin{abstract}
In order to enhance the aeroelastic stability of a tiltrotor aircraft, a structural optimization framework is developed by applying a multi-level optimization approach. Each optimization level is designed to achieve a different purpose; therefore, relevant optimization schemes are selected for each level. Enhancement of the aeroelastic stability is selected as an objective in the upper-level optimization. This is achieved by seeking the optimal structural properties of a composite wing, including its mass, vertical, chordwise, and torsional stiffness. In the upper-level optimization, the response surface method (RSM), is selected. On the other hand, lower-level optimization seeks to determine the local detailed cross-sectional parameters, such as the ply orientation angles and ply thickness, which are relevant to the wing structural properties obtained at the upper-level. To avoid manufacturing difficulties, only a few discrete ply orientation angles and an integral number of plies are considered as constraints. A genetic algorithm is selected as the optimizer at the lower-level. Use of the upper-level optimization causes a 13-18\% increase in the flutter speed when compared to the baseline configuration. In the lower-level optimization, the optimization results were obtained considering the resulting failure margin and the location of the shear center.
\end{abstract}

$$
\begin{array}{ll}
F M & =\text { failure margin } \\
I_{b} & =\text { blade bending inertia } \\
I_{q_{w}} & =\text { wing bending generalized mass } \\
K_{q 1} & =\text { vertical bending stiffness of the wing } \\
K_{q 2} & =\text { chordwise bending stiffness of the wing } \\
K_{p} & =\text { torsional stiffness of the wing } \\
K_{p f} & =\tan \delta_{3} \\
N & =\text { number of rotor blades }
\end{array}
$$

\section{Nomenclature}

${ }^{1}$ Research Scientist, Wind Energy Department, Technical University of Denmark, Ris $\varnothing$ campus, Building 114, Roskilde, 4000, Denmark. E-mail: tkim@risoe.dtu.dk.

${ }^{2} \mathrm{Ph}$.D. Student, School of Mechanical and Aerospace Engieering, Building 301, Room 1357, Seoul National University, Seoul, 151-744, Korea. E-mail: jake30@snu.ac.kr.

${ }^{3}$ Associate Professor, School of Mechanical and Aerospace Engieering, Institute of Advanced Aerospace Technology, Building 301, Room 1418, Seoul National University, Seoul, 151-744, Korea. E-mail: ssjoon@snu.ac.kr.

${ }^{4}$ Senior Research Engineer, Rotor Team, Korea Aerospace Research Institute, 45 Eoeun-dong, Yuseong-gu, Daejeon, 305-333, Korea. E-mail: dhkim@kari.re.kr. 
$y_{w} \quad=$ wing spanwise station

$y_{w_{\text {ip }}} \quad=$ wing semi-span length

$\delta_{3}=$ pitch-flap coupling parameter of the rotor

$\eta_{w} \quad=$ wing bending mode shape

$\Omega \quad=$ rotor rotational speed

()$^{*} \quad=$ non-dimensionalized value

()$_{w} \quad=$ wing related values

\section{Introduction}

Whirl flutter instability, which is induced by in-plane hub forces, generally imposes a limit on the maximum forward flight performance in a tiltrotor aircraft. Therefore, many studies have been conducted using both numerical and experimental methods to enhance the relevant aeroelastic stability. The methodologies used to improve aeroelastic stability can be classified as either passive or active. Many studies have been based on the passive method. Hall examined passive control methodologies numerically, such as pitch-flap coupling and pylon stiffness parameters [1]. The stability of the proprotor pylon system was affected to a certain degree by these control methods. The design of the rotor blade in a tiltrotor aircraft was also modified to improve the margin of the aeroelastic stability by Acree et al. [2-5]. Nixon investigated the influences of different parameters on the whirl flutter speed with a composite beam model $[6,7]$. Johnson studied the influence of coupled wing modes and rotor blade torsion degrees of freedom [8,9]. Various kinematic couplings were also studied to expand the flight envelope $[10,11]$. Regarding the active methodologies, Generalized Predictive Control (GPC), a digital time-domain multiinput multi-output predictive control scheme, was experimentally investigated to evaluate the effectiveness of an adaptive control algorithm. Active control was introduced into a fixed-system swashplate using three high-frequency servo-controlled hydraulic actuators mounted aft of the swashplate inside the pylon fairing [12, 13]. The GPC algorithm was highly effective in increasing the stability of the critical wing mode in the model tested. However, it was found to be a very complex algorithm and hence was not an attractive alternative. Recently, another active control algorithm which utilized the actuation of the wing flaperon and the rotor swashplate was examined for whirl flutter stability and robustness augmentation [14, 15]. Full-state feedback composed of a Linear Quadratic Regulator (LQR), optimal control and wing-state feedback control strategies were used in that investigation. Mueller et al. investigated several different types of control algorithms, including the Single-Input Single-Output (SISO), GPC, and Linear Quadratic Gaussian with Loop Transfer Recovery (LQG/LTR) algorithms, to improve the whirl flutter speed [16].

It is generally known that both the wing and rotor characteristics jointly influence the whirl flutter aeroelastic stability of a tiltrotor aircraft. Therefore, to augment whirl flutter aeroelastic stability effectively, simultaneous optimized designs considering multiple objectives, such as for the wing and rotor, need to be considered in a balanced manner. Recently, two different design optimization studies were conducted to improve the aeroelastic stability. Both investigations included an examination of the design parameters available for a tiltrotor aircraft [15, 17]. However, neither of these studies considered detailed configurations of the composite wing and rotor. In contrast, a design optimization framework for a tiltrotor aircraft composite wing was developed to minimize the structural weight of a tiltrotor composite wing [18]. In that approach, only the design of a simplified cross-sectional configuration of a tiltrotor aircraft composite wing was investigated. A detailed aeroelastic stability analysis was not carried out. Only the variation trend of the flutter stability with respect to optimized structural properties was examined.

In this paper, a new two-level optimization approach is proposed to account for multiple jointly folded objectives and thus hierarchical design aspects. The resulting divided stages are referred to here as the upper- and lower-level optimization stages. Each of these two optimization stages undertakes the global aeroelastic optimization of the entire aircraft/wing as well as a local structural design of the composite main wing. While each level of optimization is established, a few important elements included in the framework, such as the three-dimensional strain recovery module, will be developed and validated in parallel. 


\section{Optimization Framework}

A two-level optimization framework will be established in order to design a composite wing for a tiltrotor aircraft to enhance the whirl flutter stability while taking into account the structural aspects. A flowchart of the present two-level optimization framework is depicted in Figure 1. In the framework, the structural properties of a tiltrotor composite wing are obtained by upper-level optimization, which maximizes the flutter speed of the tiltrotor aircraft. The aeroelastically optimized wing structural properties obtained by the upper-level optimization scheme will be transferred to the lower-level optimization process as an objective function. During the lower level optimization process, the detailed cross-sectional design values for a composite wing will be determined. When the result of the lower-level optimization does not satisfy the design requirements, the process will return to the upperlevel optimization scheme. This type of iterative process will be performed until all the design results satisfy the required criteria. Details about each level in the present optimization scheme are explained below.

\subsection{Upper-level optimization}

The objective of the upper-level process is to determine the optimized structural properties of a tiltrotor composite wing. These parameters as selected in the present paper are as follows: the wing vertical ( $\left.K_{q 1}\right)$ and chordwise $\left(K_{q 2}\right)$ bending stiffness, the torsional stiffness $\left(K_{p}\right)$, the wing mass $\left(m_{w}\right)$, and the amount of pitch-flap coupling $\left(\delta_{3}\right)$ of the rotor blade to achieve the maximum whirl flutter speed $\left(V_{F}\right)$ in a tiltrotor aircraft. Among these, pitch-flap coupling is one of the most important parameters. It influences the frequency of the rotor blade flapping. The allowable movement limit for the wing stiffness is selected as $\pm 25 \%$ of its original values [19]. However, the allowable movement limit for the pitch-flap coupling parameter is chosen by conducting a sensitivity analysis because the selection of the parameters influences the optimum solution of the entire aircraft. In this paper, all of the physical values are non-dimensionalized, as follows:

$$
K_{p f}^{*}=\tan \delta_{3}, I_{q_{w}}^{*}=\frac{\int_{0}^{y_{\text {wip }}} m_{w} \eta_{w}^{2} d y_{w}}{(N / 2) I_{b}}, K_{q 1}^{*}=\frac{K_{q 1}}{(N / 2) I_{b} \Omega^{2}}, K_{q 2}^{*}=\frac{K_{q 2}}{(N / 2) I_{b} \Omega^{2}}, \text { and } K_{p}^{*}=\frac{K_{p}}{(N / 2) I_{b} \Omega^{2}}
$$

where, $\eta_{w}\left(y_{w}\right)=y_{w}{ }^{2} / y_{w_{t i p}}$ is the wing bending mode shape normalized by a wing semi-span length( $\left.y_{w_{t i p}}\right)$, and $y_{w}$ is a wing spanwise location [20].

To predict the whirl flutter speed, an aeroelastic stability analysis needs to be performed. In the present paper, an existing aeroelastic analysis based on a rigid blade structural model with full unsteady aerodynamics is used [17, 21 , 22]. The present optimization formulation can be expressed as shown below.

$$
\begin{array}{ll}
J=\max \left\{V_{F}\right\} & \\
\text { subjected to }: & I_{q_{w \text { lower }}}^{*} \leq I_{q_{w}}^{*} \leq I_{q_{w} \text { upper }}^{*} \\
& K_{q 1_{\text {lower }}}^{*} \leq K_{q 1}^{*} \leq K_{q 1_{\text {upper }}}^{*} \\
& K_{q 2_{\text {lower }}^{*}}^{*} \leq K_{q 2}^{*} \leq K_{q 2_{\text {upper }}}^{*} \\
& K_{p_{\text {lower }}}^{*} \leq K_{p}^{*} \leq K_{p_{\text {upper }}}^{*} \\
& K_{p f_{\text {lower }}}^{*} \leq K_{p f}^{*} \leq K_{p f_{\text {upper }}}^{*}
\end{array}
$$

One of the simple statistical methods, the response surface methodology (RSM), is adopted for the present upper-level optimization process. RSM is a statistical method that is used to construct approximations [23]. These approximations, known as response surfaces, are created by sampled numerical experiments over the design space [24]. Typically, the response surface is obtained as polynomials whose orders are identical to the number of design variables used. The present optimization problem then becomes separated from the aeroelastic analysis to provide an optimal solution. It was reported that an aeroelastic analysis was one of the elements that required most of the total time and computing resources in the present type of optimization problems $[19,25]$. In contrast, RSM requires less aeroelastic computation compared to other optimization algorithms. It is also beneficial in that it reduces the 
computational cost of the optimization. RSM is an empirical model which requires a collection of mathematical and statistical results in order to provide an optimized response of the system, $f$, with respect to $n$ inputs to the system, and $x$ (independent variables) [26]. Generally, response surfaces are approximated by lower-order polynomials, of either the first or second order, due to the fact that a lower-order smooth polynomial response surface removes the spurious minima and maxima while capturing the global trend of the response, thereby, leading to a robust optimal design.

In this paper, a second-order polynomial surface is constructed as follows:

$$
f(x)=A_{0}+\sum_{i=1}^{n} A_{i} x_{i}+\sum_{i=1}^{n} \sum_{j=1}^{i} A_{i j} x_{i} x_{j}
$$

where, $A_{0}, A_{i}$, and $A_{i j}$ are regression coefficients, and $n$ is the number of design variables used.

A second-order response surface involves $[\{n(n+1) / 2\}+n+1]$ regression coefficients. Therefore, twenty-one regression coefficients are used because five design variables are considered, as shown in Eq. (4). The final form of the second-order polynomial is presented as follows:

$$
\begin{aligned}
f\left(x_{1}, x_{2}, x_{3}, x_{4}\right) & =A_{0}+A_{1} x_{1}+A_{2} x_{2}+A_{3} x_{3}+A_{4} x_{4}+A_{5} x_{5}+A_{11} x_{1}^{2}+A_{22} x_{2}^{2}+A_{33} x_{3}^{2}+A_{44} x_{4}^{2}+A_{55} x_{5}^{2} \\
+ & A_{12} x_{1} x_{2}+A_{13} x_{1} x_{3}+A_{14} x_{1} x_{4}+A_{15} x_{1} x_{5}+A_{23} x_{2} x_{3}+A_{24} x_{2} x_{4}+A_{25} x_{2} x_{5} \\
+ & A_{34} x_{3} x_{4}+A_{35} x_{3} x_{5}+A_{45} x_{4} x_{5}
\end{aligned}
$$

To evaluate the unknown regression coefficients in Eq. (4), a fitting method will be introduced [26]. The choice of the data points to produce a high-fidelity response surface is important in this case. Therefore, a central composite design (CCD) is considered to select the optimal design points [26]. Figure 2 shows an example illustration of CCD for a case involving two variables, in which $\alpha$ describes the distance between the axial points and the center. In general, $\alpha$ is obtained as the square root of the number of design variables; therefore, $\alpha$ is $\sqrt{5}$ in this example.

\subsection{Lower-level optimization}

Determination of the detailed cross-sectional parameters for a composite wing, such as the layup configurations, shear web positions, and ply thickness, is the purpose of the lower-level optimization process. In this paper, it is assumed that a single cross-sectional design is constantly applied through the entire span of a wing. Thus, the design of such a typical section represents the characteristics of the entire wing.

Among the aeroelastically optimized structural properties obtained by the upper-level optimization the wing structural properties, such as the wing bending generalized mass $\left(I_{q_{w}}^{*}\right)$, the wing vertical bending stiffness ( $\left.K_{q 1}^{*}\right)$, wing chordwise bending stiffness ( $K_{q 2}^{*}$ ), and wing torsional stiffness $\left(K_{p}^{*}\right)$ are used in the lower-level optimization process as an objective function. The objective function established in the present lower-level optimization process is expressed in Eq. (5). The objective function is to minimize the difference between the target properties and the predicted properties.

$$
\begin{array}{r}
J=\min \left[w_{1} a b s\left(\frac{I_{w_{\text {target }}}^{*}-I_{q_{w}}^{*}}{I_{q_{w} \text { target }}^{*}}\right)+w_{2} a b s\left(\frac{K_{q 1_{\text {target }}}^{*}-K_{q 1}^{*}}{K_{q 1_{\text {target }}}^{*}}\right)+w_{2} a b s\left(\frac{K_{q 2_{\text {target }}}^{*}-K_{q 2}^{*}}{K_{q 2_{\text {target }}}^{*}}\right)\right. \\
\left.+w_{2} a b s\left(\frac{K_{p_{\text {target }}}^{*}-K_{p}^{*}}{K_{p_{\text {target }}}^{*}}\right)-w_{3} F M\right]
\end{array}
$$

In Eq. (5), FM is the failure margin. More details about the failure margin will be given below. There are three different weighting coefficients used: $w_{1}, w_{2}$, and $w_{3}$. These weighting coefficients force all of the terms in the objective functions to be minimized efficiently. The appropriately selected values of the weighting factors were found to be $0.2941,0.5882$, and 0.1176 , respectively. 
In addition to the wing structural properties determined by the upper-level optimization process, the failure margin $(F M)$, as defined in Eq. (6), is also included in the objective function. In contrast to the other design variables, $F M$ will be maximized during the lower-level optimization process.

$$
\text { Failure margin }=\frac{\text { Material allowable strain }- \text { Estimated maximum strain }}{\text { Material allowable strain }}
$$

As part of the lower-level optimization process, the failure margin is evaluated by the aforementioned strain recovery analysis. As part of this process, the presently optimized cross-sectional design values will not only satisfy the target wing detailed cross-sectional design parameters, but they also have a sufficient failure margin.

In this paper, as shown in Figure 3, twenty-seven cross-sectional design parameters are considered in the lowerlevel optimization process, as follows: two spar cap positions (one for the forward and the other for the aft position), twelve ply angles (four for the spar caps and the remaining eight for the each shear web) in which the ply angle for the skin is fixed at $0^{\circ}$, and thirteen ply sheets (one for the skin, four for the spar caps, and eight for the each shear web). The fore shear web, which is close to the leading edge, was found to be between $0.15 c$ and $0.27 c$ while the rear shear web is between $0.28 c$ and $0.45 c$. Table 1 summarizes the design variables used in the lower-level optimization process along with the corresponding upper and lower boundaries.

To improve the accuracy and reliability, several constraints are considered during the optimization. First, the ply orientation angles are restricted to only a few discrete values, in this case $0, \pm 30, \pm 45, \pm 60$ and $\pm 90^{\circ}$, to prevent possible manufacturing difficulties, which would occur for unusual ply orientation angles. Second, only integer values for the number of plies are considered. Third, the shear center of the wing must be located between $0.22 c$ and $0.30 c$ to ensure the classical bending-torsion type aeroelastic stability of a fixed wing aircraft. Finally, the materials used in the wing structure are also fixed. When a single material is used, it would be difficult to satisfy the mass and stiffness requirements simultaneously. Therefore, two different materials, E-glass and T300/5280 graphite-epoxy, are used in the present wing design.

To conduct the structural integrity analysis upon the optimized composite wing cross-section, a threedimensional strain recovery module is developed, as shown in Figure 4. First, a strain influence matrix and a stiffness matrix are obtained by executing a cross-sectional analysis, here the Variational Asymptotic Beam Sectional analysis (VABS) [27]. The strain influence matrix is composed of the influencing coefficients of the local strain vector with respect to each beam deformation measured. The local strain vectors are obtained upon the reference point of each beam cross-section. Then, using the inverse form of the one-dimensional global beam constitutive relationship, Eq. (7), the strain and curvatures are obtained at a wing station as a function of the internal force and moment.

$$
\left\{\begin{array}{l}
\gamma_{1} \\
\kappa_{1} \\
\kappa_{2} \\
\kappa_{3}
\end{array}\right\}=[K]^{-1}\left\{\begin{array}{l}
F_{1} \\
M_{1} \\
M_{2} \\
M_{3}
\end{array}\right\}
$$

In Eq. (7), $[K]$ is the stiffness matrix obtained from VABS. $\gamma_{1}$ is the axial strain, $\kappa_{1}$ is the elastic twist, and $\kappa_{2}$ and $\kappa_{3}$ are the two bending curvatures. The internal forces and moments at each wing section are predicted by applying the Comprehensive Analytical Model of Rotorcraft Aerodynamics and Dynamics II (CAMRAD II) [28]. The present analysis consists of an airframe and two rotors. The analysis is conducted in a free flight trim condition. The trim variables are the collective, longitudinal and cyclic pitch angles. The trim target quantities are the longitudinal force, vertical force, and pitching moment of the aircraft. The strain and curvatures obtained at a few wing stations are multiplied by the strain influence matrix for each wing element obtained from the threedimensional strain recovery process [29]. Each component of the strain influence matrix is the strain corresponding to classical unit deformation. In addition, a safety factor of 1.5 is considered. The maximum strain criterion will then be applied for each component in the resulting strain and compared to the allowable values for the local constituent material.

Figure 5 shows a flowchart of the lower-level optimization procedure. In order to perform the optimization, a genetic algorithm included in the MATLAB Global Optimization Toolbox [30] is adopted. A genetic algorithm, a 
type of global optimization method, is a stochastic search technique that imitates the natural evolution process. Convergence upon the objective function will generally becomes less sensitive when a global optimization process is used.

\section{Numerical Results}

In this paper, a semi-span full-scale XV-15 tiltrotor aircraft with a gimbaled stiff-in-plane three-bladed rotor is modified in terms of its wing design to improve its aeroelastic stability by applying the present optimization approach. The XV-15 aircraft originally adopts an aluminum wing, but it is replaced here with a new composite wing. Table 2 summarizes the aircraft properties used [20]. The results obtained from each level of the optimization scheme are described below.

\subsection{Upper-level optimization}

To determine the allowable movement limit for the pitch-flap coupling parameter, a sensitivity analysis is conducted. Figure 6 shows the maximum flutter speed predicted for the full-scale XV-15 aircraft in terms of $\delta_{3}$ in the range of $-30^{\circ}\left(K_{p f}^{*}=-0.5774\right)$ and $30^{\circ}\left(K_{p f}^{*}=0.5774\right)$. It was observed that the flutter speed reached its maximum limit between $-5^{\circ}\left(K_{p f}^{*}=-0.0875\right)$ and $0^{\circ}\left(K_{p f}^{*}=0\right)$. Therefore, those values were selected as the allowable movement limit for the pitch-flap coupling parameter.

Table 3 lists the physical and coded values for the five design variables. Also, the upper and lower boundaries of the allowable movement limit for these design variables are provided. The maximum possible whirl flutter speed of the tiltrotor aircraft, $V_{F}$, is determined by scanning twenty seven design points selected from the present CCD. Table 4 lists the selected design points. The unknown regression coefficients in Eq. (4) are determined by minimizing the least-square values of the present design points listed in Table 4 [26]. The second-order response surface is then constructed as follows:

$$
\begin{aligned}
f\left(x_{1}, x_{2}, x_{3}, x_{4}\right)=361.188 & -2.5085 x_{1}-0.215 x_{2}-1.9535 x_{3}+2.0459 x_{4}+7.4086 x_{5} \\
& -2.6849 x_{1}^{2}-0.1253 x_{2}^{2}+0.088 x_{3}^{2}-0.5519 x_{4}^{2}-0.7652 x_{5}^{2} \\
& +0.8126 x_{1} x_{2}+1.4638 x_{1} x_{3}+0.1216 x_{1} x_{4}-1.5774 x_{1} x_{5}+0.7498 x_{2} x_{3} \\
& -0.0409 x_{2} x_{4}-1.0577 x_{2} x_{5}+0.1976 x_{3} x_{4}-1.0577 x_{3} x_{5}-0.7911 x_{4} x_{5}
\end{aligned}
$$

Table 5 shows the predicted responses with respect to five inputs to the system. In the table, the difference between the response from the aeroelastic analysis and the response from the RSM is estimated. This difference explains the amount of the lack of fitting of the created response surface. The average difference in the response surface obtained is approximately $0.25 \%$.

With the obtained response surface, an optimal design point to maximize the whirl flutter speed will be determined. A second-order response surface has only a single stationary point which can be a global maximum, a global minimum, or a saddle point. In order to investigate the stationary point, a Hessian matrix which contains the second-order partial derivatives of the response surface is used [31]. The eigenvalues of the Hessian matrix in Eq. (8) help to explain the characteristics of the stationary point. If all of the eigenvalues are positive, the stationary point will be the global minimum. If all of the eigenvalues are negative, the stationary point will be the global maximum. If all the eigenvalues have different signs, the stationary point will be the saddle point. The eigenvalues of the Hessian matrix considered here are $\lambda_{1}=-6.1367, \lambda_{2}=-2.4737, \lambda_{3}=-0.9252, \lambda_{4}=-0.7441$, and $\lambda_{5}=2.2012$. The stationary point of the current response surface was found to be a saddle point. Therefore, an exhaustive search of the design surface is required to find the global maximum [32]. Figure 7 shows the variation of the response surface objective function with respect to the design variables considered. In Figure 7(a), the wing chordwise bending and torsional stiffness and the wing bending generalized mass values were found to be constant with the zero-coded values, as shown in Table 4, while the pitch-flap coupling and wing vertical stiffness varied within their movement limits. As shown in Figure 7(b), the wing bending generalized mass and the wing torsional stiffness were found to vary while the other variables remained at their baseline values. In Figure 7(c), the wing chordwise stiffness and the wing torsional stiffness are shown to vary, whereas the pitch-flap coupling, wing bending generalized mass, and wing vertical stiffness maintain at their baseline values. From these figures, it is apparent that the objective function, 
the whirl flutter speed of the aircraft, will be maximized when less pitch-flap coupling, a lighter wing, a softer wing in terms of the vertical and chordwise directions, and a stiffer wing in the torsional direction are applied.

The optimum values of the design variables are presented in Table 6. Using the optimum design variables, the updated whirl flutter speed of the aircraft obtained was approximately $192 \mathrm{~m} / \mathrm{sec}$. Compared to the baseline results obtained by the same aerodynamic model used in Table 7, the present optimized flutter speed is increased by approximately $13 \%$. Compared to that using the normal quasi-steady aerodynamics, the flutter speed is increased by approximately $18 \%$. Based on the optimized design variables from the upper-level stage, lower-level optimization will be performed to find the optimal design of the composite wing.

\subsection{Lower-level optimization}

Once the upper-level optimization process is completed, the optimized design results, i.e., four wing detailed cross-sectional design parameters $\left(I_{q_{w}}^{*}, K_{q 1}^{*}, K_{q 2}^{*}\right.$ and $\left.K_{p}^{*}\right)$, are transferred and used as target values for the objective function in the lower-level optimization. In this paper, a single cross-section, NACA 64A223, which is an airfoil of the original XV-15 aircraft, is considered.

Initially, validation of the present failure analysis module was conducted. Subsequently, to perform the strain recovery analysis, the internal forces and moments at each wing section were obtained. Lower-level optimization including the validated failure analysis was then conducted using the obtained internal forces and moments.

\subsubsection{Validation of the present failure analysis}

Validation of the present recovery analysis was conducted, as described in detail in the literature [33]. The present result was compared to those obtained by a two-cell thin-walled beam section analysis [34]. The two-cell thinwalled analysis is based on the asymptotically correct formulation stemming from shell theory. Figure 8 shows a schematic of a sample composite wing cross-section temporarily created for the present validation. NACA0015 was selected as the baseline airfoil shape and glass fiber was applied to all of the regions. The composite wing cross section consists of a spar and a skin. Table 8 summarizes the validation results. The stiffness result shows good agreement with the results obtained from the two-cell thin-walled analysis, but the strain results show a certain discrepancy. This resulted from the difference in the theoretical formulation between VABS and the two-cell thinwalled analysis.

\subsubsection{Wing loads analysis by CAMRAD II}

To perform the strain recovery analysis as part of the lower-level optimization process, the internal forces and moments at each wing section need to be obtained. The internal forces and moments at each wing section are predicted by CAMRAD II under a cruise flight condition at $170 \mathrm{~m} / \mathrm{sec}$. The maximum cruise flight speed of the XV15 aircraft in all range of altitude was originally reported to be $154 \mathrm{~m} / \mathrm{sec}$ [35]. However, in this paper, a CAMRAD II prediction was conducted at a flight speed of $170 \mathrm{~m} / \mathrm{sec}$, which is the maximum cruise flight speed increased by $10 \%$, to provide a more conservative prediction. In this paper, the CAMRAD II input file for the XV-15 aircraft provided in the literature [2] was used for the air load prediction. This CAMRAD II input consisted of an airframe and two rotors. In more detail, the wing and fuselage are included in the airframe and are described in terms of the mass, inertia, and mode shapes. The internal loads existing in the wing structure are estimated by predicting the external aerodynamic loads, which are in this case the lift, drag, pitching moment, and thrust acting upon the wing and rotors. More specifically, vertical bending moment is generated from the lift on the wing, the rotor weight, and the torque by the rotors. The chordwise bending moment is from the drag on the wing and the thrust by the rotors. The torsional moment is from the pitching moment in the trim condition. However, there is a limitation when using this type of airframe model. When the wing is included in the airframe, a prediction of the internal loads is not possible in CAMRAD II merely by attaching the load sensors directly. Thus, in this analysis, due to this limitation, it is assumed that the lift and drag on the wing are uniform along the spanwise direction. In the future, the wing will be analyzed as one of the rotors, instead of an airframe, to evaluate more realistically the distribution of the lift and drag along the wing. Then, it is expected that the detailed structural properties at each spanwise location will be considered in the analysis. Load sensors will be attached and used at each spanwise location of the wing.

The present input file was validated with the result with the normal rated power limit of the engine installed in an XV-15 aircraft. At sea level, its normal rated power limit was reported to be 2,500 hp and the maximum flight speed of the aircraft was $134 \mathrm{~m} / \mathrm{sec}$ [35]. When the present input file is used and trimmed to the same rating of $134 \mathrm{~m} / \mathrm{sec}$ at sea level, the estimated rotorcraft required power becomes 2,516 hp. The difference between the engine normal 
rated power and the rotorcraft required power predicted by the present input file is approximately $0.64 \%$. Therefore, it is concluded that the present CAMRAD II input file used to simulate the XV-15 aircraft is sufficiently reliable, as are the aerodynamic prediction results when using it. Using the aerodynamic prediction results, the internal forces and moments at each wing section were estimated by applying the Euler-Bernoulli beam formulation in the cantilevered boundary condition. Table 9 summarizes the resulting internal forces and moments predicted at each wing section. In the cantilevered boundary condition, the vertical and chordwise bending moment will be in a nonuniform distribution when distributed loads are applied.

\subsubsection{Result of the lower-level optimization}

Using the internal forces and moment predicted at each wing section, lower-level optimization including the validated failure analysis module is conducted. As a result, two cases, Case I and II, are examined by changing the materials used. E-glass is used for the skin in both cases. In Case I, T300/5280 graphite-epoxy is used for the spar caps and E-glass is used for the shear webs. In contrast, E-glass is used for the spar caps and T300/5280 graphiteepoxy is used for the shear webs in Case II. A single prepreg ply features a thickness of $1.27 \times 10^{-4} \mathrm{~m}$. Table 10 shows the material properties and maximum allowable strain values of both the E-glass and T300/5280 graphite-epoxy.

The optimum cross-sectional design values for Case I and II are illustrated in Figures 9 and 10, respectively. In Case I (Figure 9), the fore shear web is located at $0.24 c$ and the rear one is at $0.37 c$. The ply orientation angles are accordingly $\left[0_{9}\right],\left[-45_{6} / 45_{8} / 30_{6} /-45_{27}\right]_{\mathrm{s}},\left[45_{19} / 90_{2} / 0_{15} / 45_{8}\right]_{\mathrm{s}}$, and $\left[90_{1} /-45_{3} / 90_{17} / 45_{3}\right]_{\mathrm{s}}$ for the skin, spar caps, fore shear web, and rear shear web, respectively. A symmetric ply stack sequence is used for the spar caps and the shear webs. The result for Case II is illustrated in Figure 10. The fore shear web is located at $0.22 c$ and the rear one is at $0.31 c$, respectively. The ply orientation angles obtained are $\left[0_{8}\right],\left[0_{7} /-45_{19} / 90_{2} /-90_{9}\right]_{\mathrm{s}},\left[-30_{6} /-30_{4} / 45_{22} / 0_{7}\right]_{\mathrm{s}}$ and $\left[60_{16} /-30_{13} /-\right.$ $\left.45_{19} / 30_{14}\right]_{\mathrm{s}}$, for the skin, spar caps, fore shear web, and aft shear web, respectively. Table 11 shows the wing structural properties estimated using the optimized cross-sectional design parameters. The target values used here were previously obtained in the upper-level optimization illustrated in Table 6 in Section 3.1. Also, the differences are shown between the target and the present wing structural properties for Cases I and II, respectively. It was found that the wing detailed cross-sectional design parameters obtained by the optimized cross-sectional design parameters are quite close to the target values in both cases. However, the failure margin resulting from the two optimal design configurations are significantly different from each other. In Case I, the maximum failure margin of the wing was found to be about 0.60 , whereas in Case II, it is approximately 0.27 signifying a lower strain withstanding capacity before failure. Moreover, the shear center is located at $0.26 c$ in Case I, but in Case II it is located at $0.29 c$. It was originally desired for the shear center to be located at $0.25 c$ for the sake of classical bending-torsion type aircraft aeroelastic stability. Therefore, it is now concluded that the result corresponding to Case I is the better optimization result considering the failure margin and the shear center location.

\section{Conclusions}

A structural design optimization framework is developed by suggesting a two-level approach for a composite wing to improve the aeroelastic stability of a tiltrotor aircraft. It is known that both the wing and rotor characteristics influence the whirl flutter stability of a tiltrotor aircraft. Therefore, simultaneous multiple objective design optimization processes need to be considered to augment the whirl flutter aeroelastic stability adequately. This type of two-level optimization process is regarded to be more appropriate for the present tiltrotor aircraft aeroelastic stability augmentation problem. In its upper-level stage, a statistical method is utilized as an optimizer to find the proper global structural properties so that the flutter speed can be increased. In the numerical validation with the XV-15 aircraft, a 13\% (approx.) increase in the flutter speed was achieved compared to the results in the baseline configuration. Based on the optimized design variables from the upper-level stage, lower-level optimization is performed to find the optimal local cross-sectional design by applying a genetic algorithm. To estimate the detailed cross sectional design parameters of a composite wing, VABS software is used. Discrete ply orientation angles and an integral value for the number of plies are considered in order to prevent manufacturing difficulties. The resulting composite wing design needs to be proved in terms of safety. Thus, a three-dimensional strain recovery module was developed and incorporated into the lower-level optimization process. Once the present design framework is established, the aluminum wing of the XV-15 aircraft will be replaced with a new composite wing by applying the framework. In the design process, two different design cases are considered by applying the composite materials of E-glass and T300/5280 graphite-epoxy. In the first case, the shear center is located at $0.26 c$. Failure margin is obtained to be about 0.60 . In the second case, approximately 0.27 failure margin is obtained. The shear center is located at $0.29 c$. The result obtained in the former case was found to be better considering the failure margin and the 
shear center location. Thus, through the lower-level optimization process, a realistic wing configuration which is compatible with the optimized wing structural properties was obtained.

In addition to the present two-level design optimization framework, subsequent updating activities are now in progress. In the upper-level optimization process, the existing in-house aeroelastic analysis will be updated to include an elastic blade structural model. When the elastic blade motion is included, it will be possible to obtain more accurate predictions of the whirl flutter stability. In the lower-level optimization process, the lift distribution on the wing is presently assumed to be uniform along its span. The resulting internal forces and moments may not be accurate in such a case. Thus, in a future wing loads analysis, the wing will be analyzed as one of the rotors rather than as an airframe in order to extract a more realistic distribution of the lift and drag.

\section{Acknowledgments}

This work is supported by Defense Acquisition Program Administration and Agency for Defense Development in Republic of Korea under the contract UD100048JD. This work is also supported by the New and Renewable Energy Program of the Korea Institute of Energy Technology Evaluation and Planning (KETEP) grant funded by the Korea government Ministry of Knowledge Economy (No.20104010100490)

\section{References}

${ }^{1}$ Hall, Jr., W. E., "Prop-Rotor Stability at High Advance Ratios," Journal of the American Helicopter Society, Vol. 11, No. 2, April 1966.

${ }^{2}$ Acree, C. W., Jr., Peyran, R. J., and Johnson, W., "Rotor Design Options for Improving XV-15 Whirl-Flutter Stability Margins," NASA Technical Paper-2004-212262, March, 2004.

${ }^{3}$ Acree, C. W., Jr., Peyran, Jr., R. J., and Johnson, W., "Rotor Design for Whirl Flutter: An Examination of Options for Improving Tiltrotor Aeroelastic Stability Margins," American Helicopter Society 55th International Annual Forum Proceedings, Alexandria, VA, May 25-27, 1999.

${ }^{4}$ Acree, C. W., Jr., "Effects of Rotor Design Variations on Tiltrotor Whirl Mode Stability," Tiltrotor/Runway Independent Aircraft Technology and Applications Specialists' Meeting, Arlington, Texas, March 20-21, 2001.

${ }^{5}$ Acree, C. W., Jr., "Rotor Design Options for Improving V-22 Whirl Mode Stability," American Helicopter Society 58th International Annual Forum Proceedings, Montréal, Quebec, Canada, June 11-13, 2002.

${ }^{6}$ Nixon, M, "Aeroelastic Response and Stability of Tiltrotors with Elastically Coupled Composite Rotor Blades," Ph.D. Thesis, University of Maryland, 1993.

${ }^{7}$ Nixon, M., "Parametric Studies for Tiltrotor Aeroelastic Stability in Highspeed Flight," Journal of the American Helicopter Society, Vol. 38, No. 4, 1993, pp. 71-79.

${ }^{8}$ Johnson, W., "Analytical Model for Tilting Proprotor Aircraft Dynamics, Including Blade Torsion and Coupled Bending modes, and Conversion Mode Operation," NASA Technical Report, NASA TM X-62,369, August, 1974.

${ }^{9}$ Johnson, W., "Analytical Modeling Requirements for Tilting Proprotor Aircraft Dynamics," NASA Technical Report, NASA TN D-6013, July, 1975.

${ }^{10}$ Moore, M. J., Yablonski, M. J., Mathew, B., and Liu, J., "High Speed Tiltrotors: Dynamics Mothodology," American Helicopter Society 49th International Annual Forum Proceedings, St. Louis, Missouri, May 19-21, 1993.

${ }^{11}$ Kim, T., Shin, S. -J., and Kim, D. H., "Influence of Geometric Coupling on the Whirl Flutter Stability in Tiltrotor Aircraft with Unsteady Aerodynamics," Journal of Aerospace Engineering, Vol. 25, No. 1, 2012, pp. 143-148.

${ }^{12}$ Kvaternik, R. G., and Kohn, J. S., "An Experimental and Analytical Investigation of Proprotor Whirl Flutter," NASA Technical Paper-1047, Dec, 1977.

${ }^{13}$ Kvaternik, R. G., Piatak, D. J., Nixon, M. W., Langston, C. W., Singleton, J. D., Bennett, R. L., and Brown, R. K., “An Experimental Evaluation of Generalized Predictive Control for Tiltrotor Aeroelastic Stability Augmentation in Airplane Mode of Flight," American Helicopter Society 57th International Annual Forum Proceedings, Washington, DC, May 9-11, 2001.

${ }^{14}$ Hathaway, E. L., "Active and Passive Techniques for Tiltrotor Aeroelastic Stability Augmentation," Ph.D. Thesis, The Graduate School College of Engineering, The Pennsylvania State University, August, 2005.

${ }^{15}$ Paik, J., and Gandhi, F., "Design Optimization for Improved Soft In-Plane Tiltrotor Aeroelastic Stability in Airplane Mode," Journal of Aircraft, Vol. 47, No. 4, 2010, pp. 1089-1099.

${ }^{16}$ Mueller, J. P., Gourinat, Y., Ferrer, R., Krysinski, T., and Kerdreux B., "A Numerical Study on Active Control for Tiltrotor Whirl Flutter Stability Augmentation,” Journal of the American Helicopter Society, Vol. 51, No. 3., 2006, pp. 244-254.

${ }^{17}$ Kim, T., "Aeroelastic Stability Analysis of Tiltrotor Aircrafts with Unsteady Aerodynamic Effect," Ph.D. Thesis, Graduate School, School of Mechanical and Aerospace Engineering, Seoul National University, Feb. 2009.

${ }^{18}$ Park, J. -S, Jung, S. N., Lee, M. -K., and Kim, J. M., "Design Optimization Framework for Tiltrotor Composite Wings considering Whirl Flutter Stability," Composite: Part B, Vol. 41, 2010, pp. 257-267.

${ }^{19}$ Ganguli, R., "Optimum Design of a Helicopter Rotor for Low Vibration Using Aeroelastic Analysis and Response Surface Methods," Journal of Sound and Vibration, Vol. 258, No. 2, November 2002, pp. 327-344.

${ }^{20}$ Johnson, W., "Dynamics of Tilting Proprotor Aircraft in Cruise Flight," NASA Technical Note D-7677, 1974. 
Figures

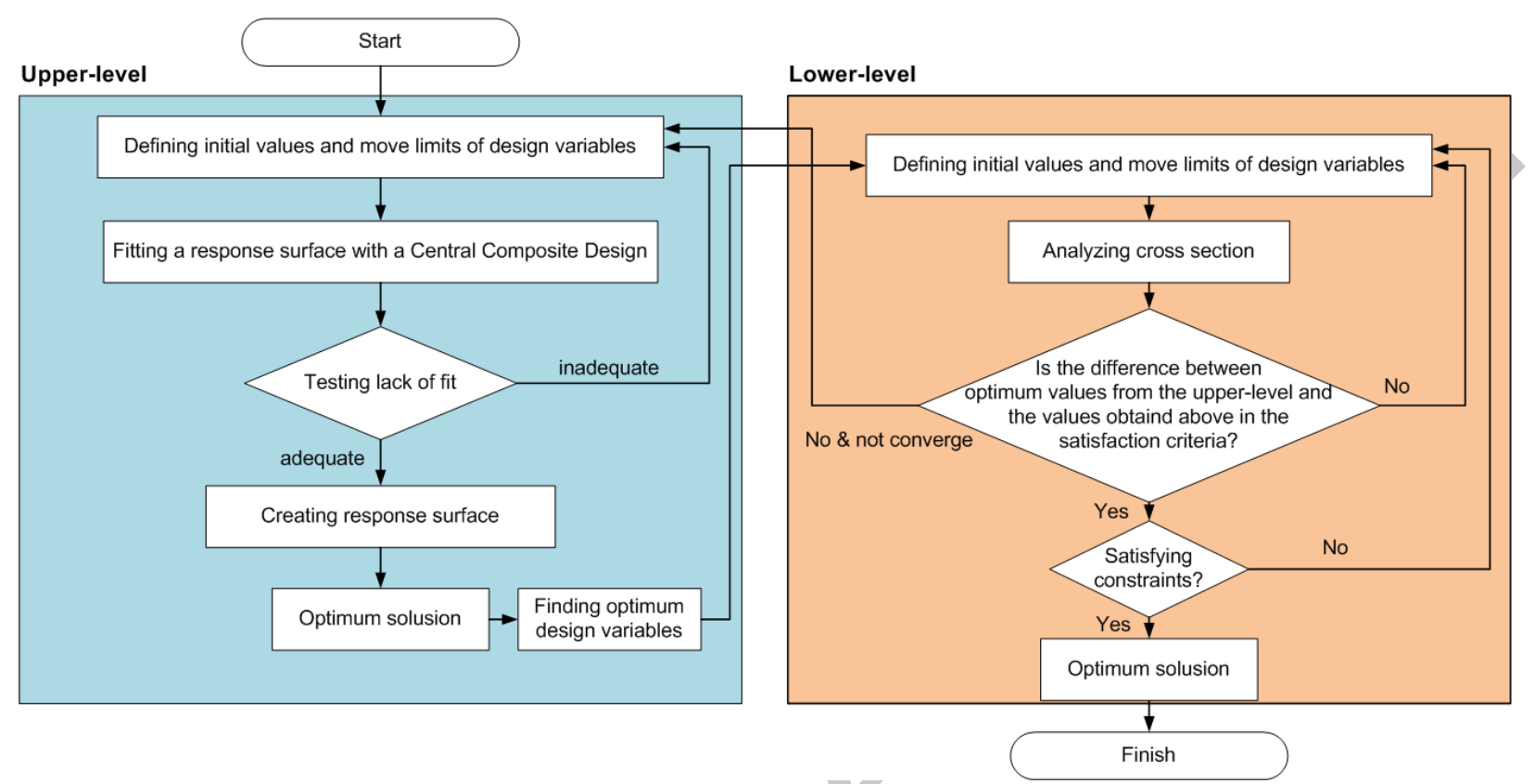

Figure 1. Flowchart of the present two-level optimization framework

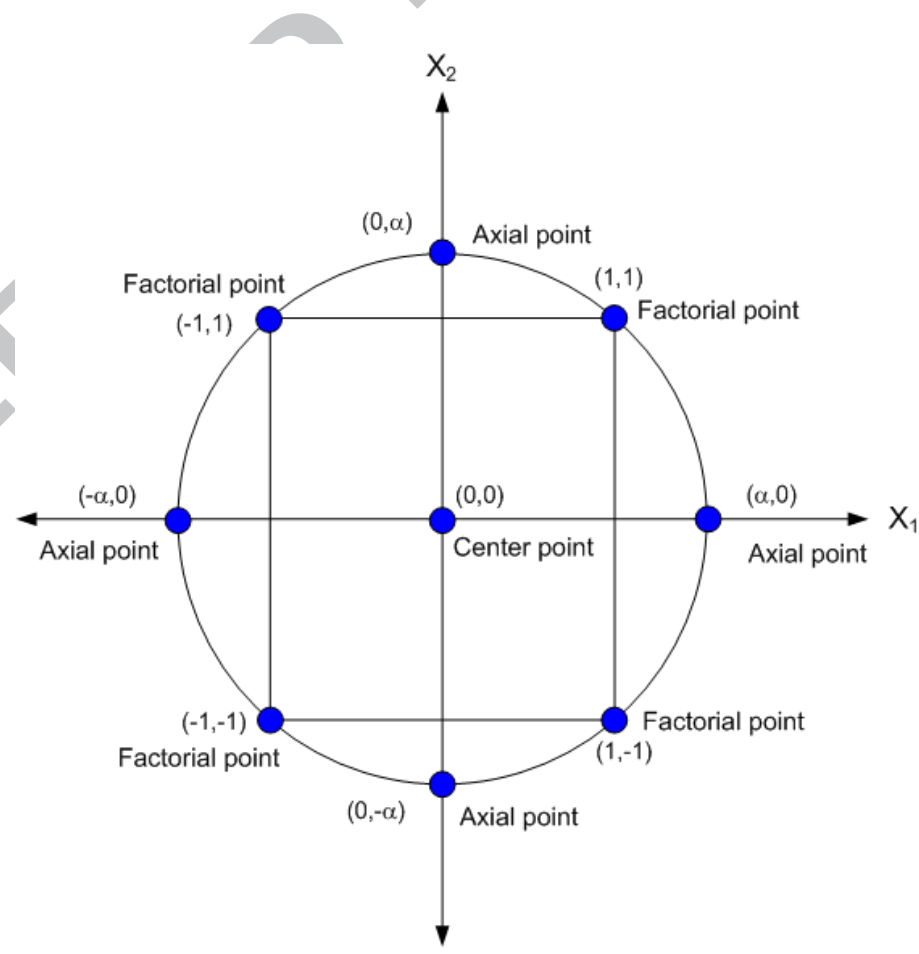

Figure 2. Example illustration of the central composite design (CCD) for two design variables 


\section{Airfoil: NACA 64A223}

Alphabet: symbol of the design variables listed in Table 2

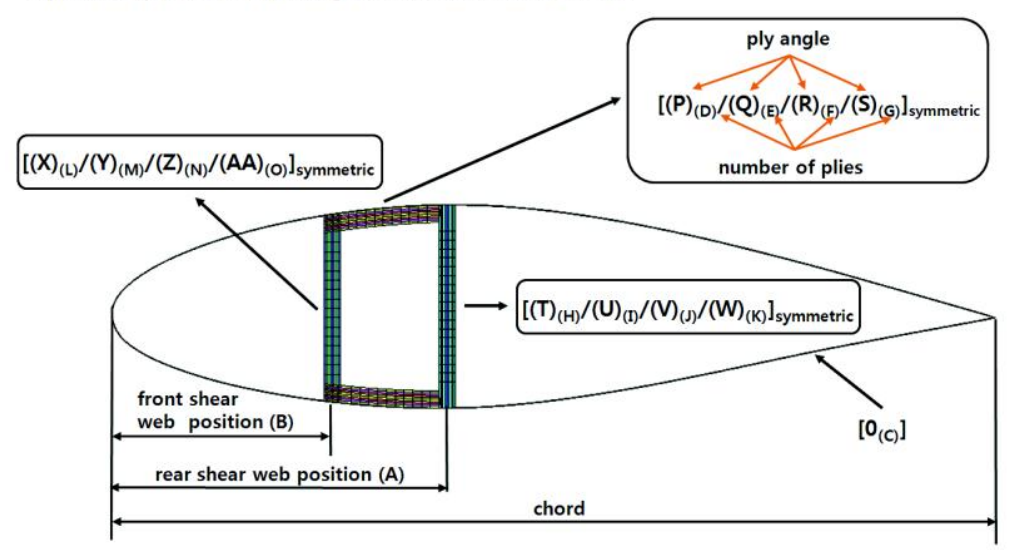

Figure 3. Schematic of the design variables used in the present lower-level optimization

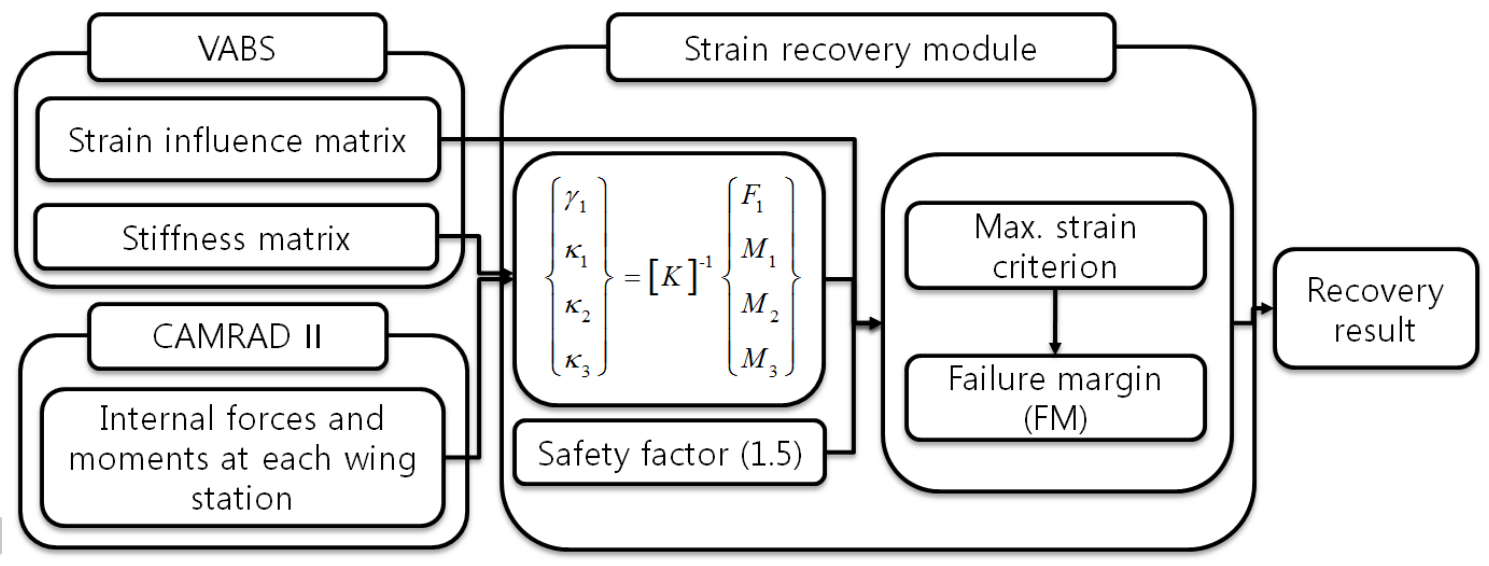

Figure 4. Flowchart of the the three-dimensional strain recovery analysis 


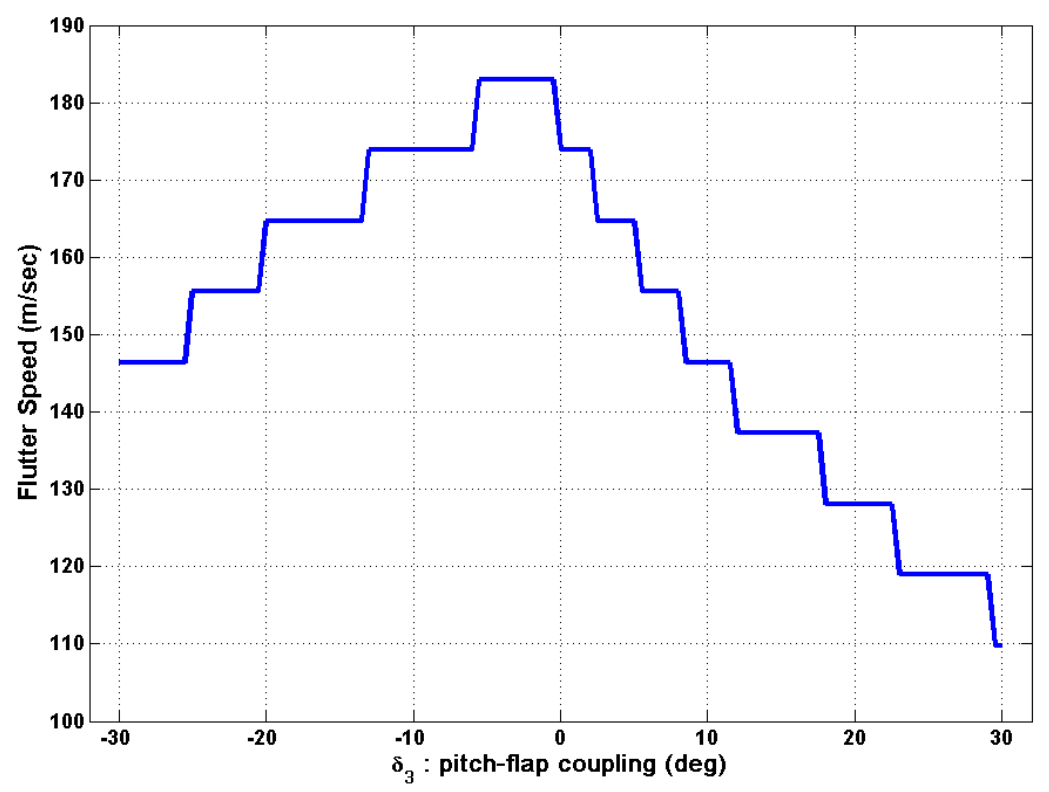

Figure 6. Sensitivity analysis result for the pitch-flap coupling 


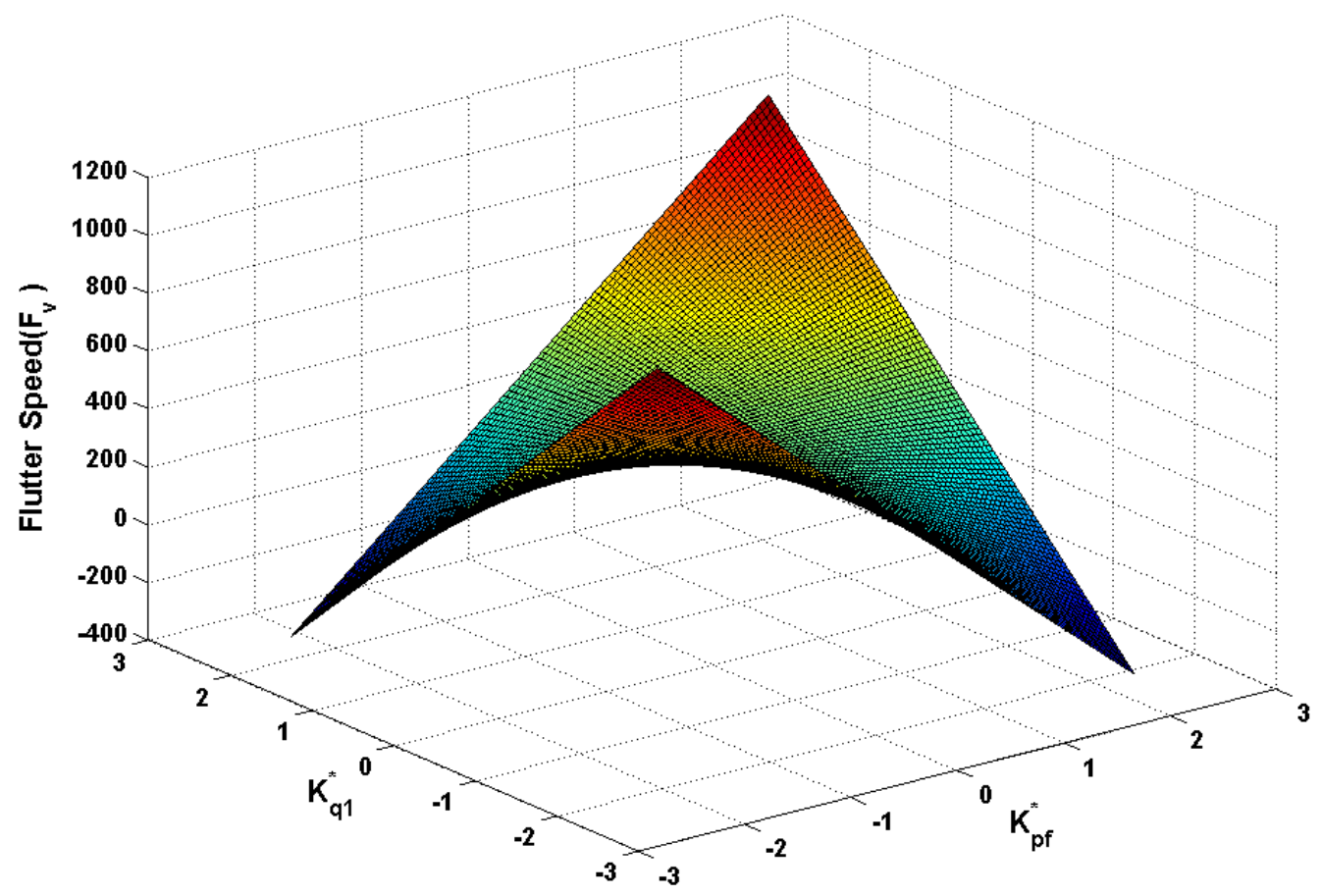

(a) Response surface with respect to the wing vertical bending stiffness and pitch-flap coupling

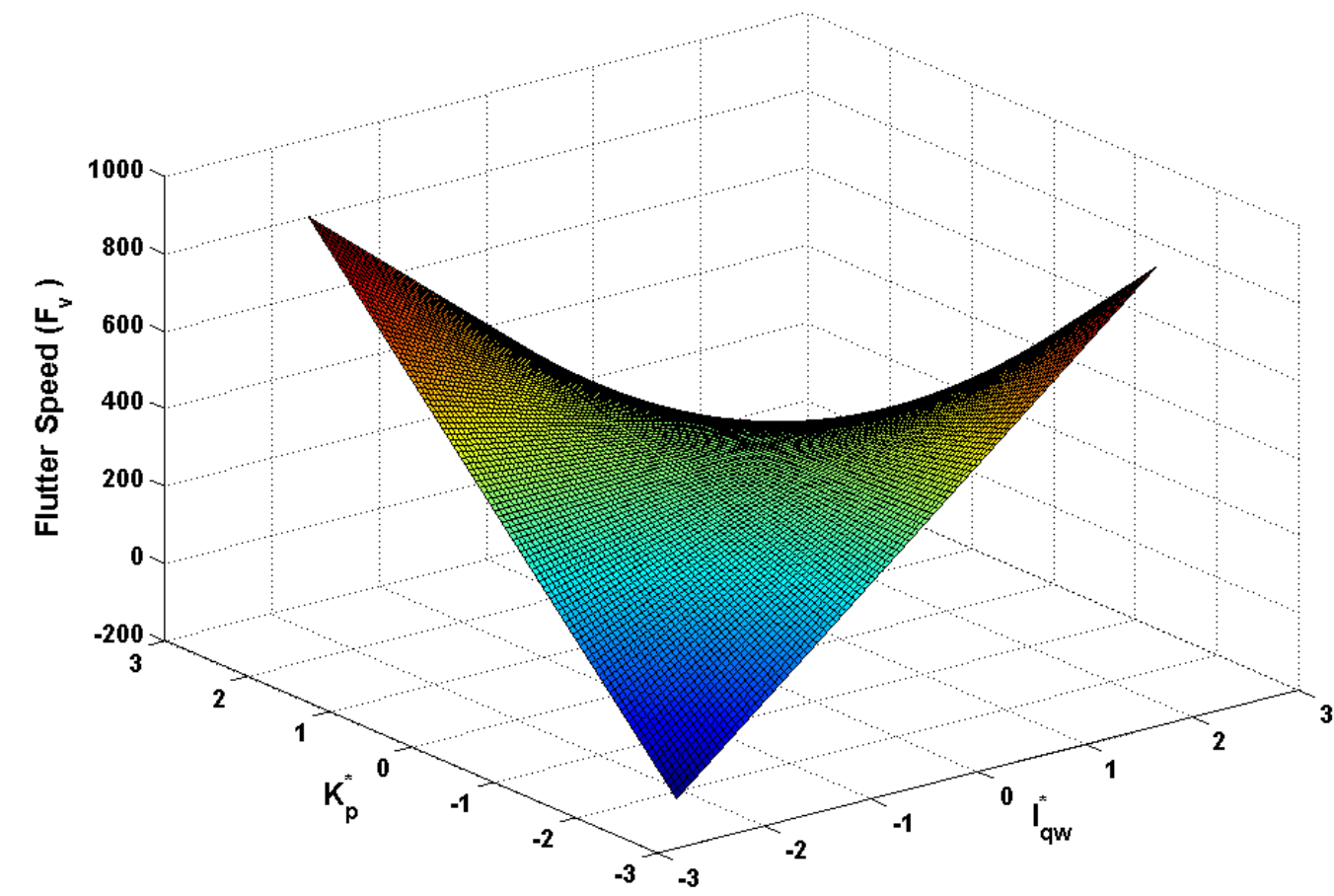

(b) Response surface with respect to the wing torsional stiffness and the wing bending generalized mass 


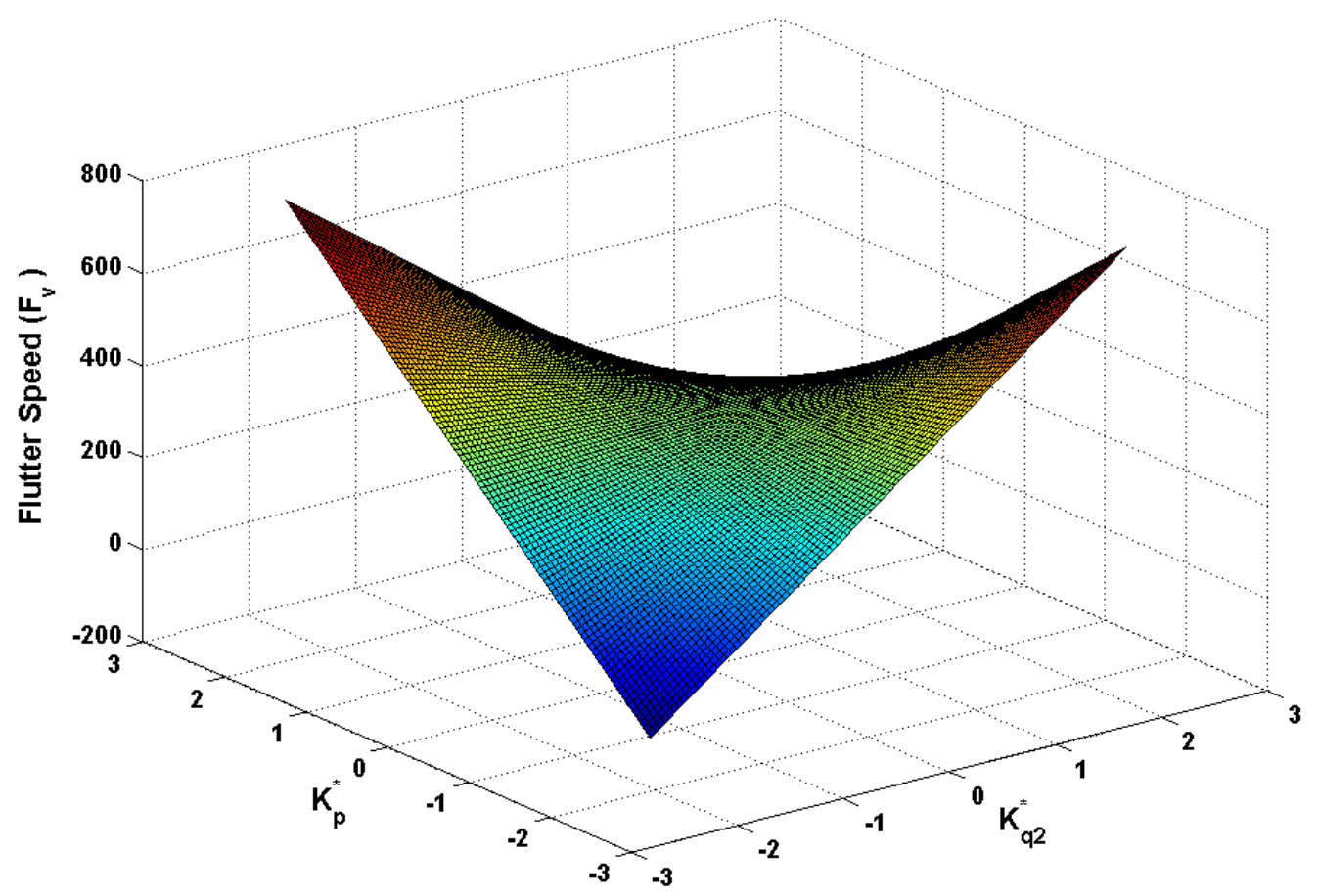

(c) Response surface with respect to the wing torsional stiffness and chordwise stiffness

Figure 7. Variations of the response surface function obtained

\section{- Airfoil: NACA 0015}

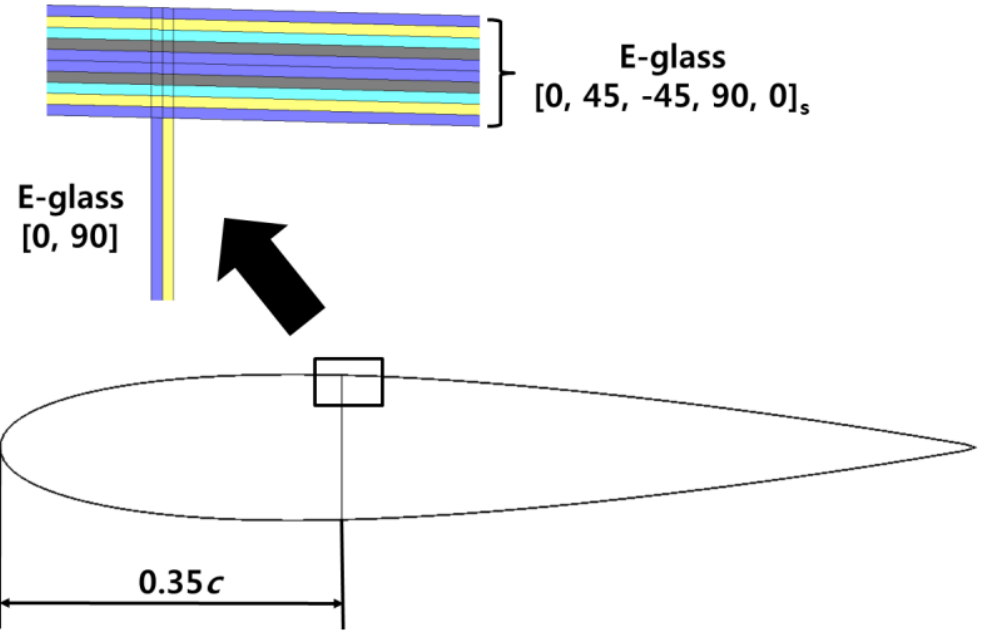

Figure 8. Cross section schematic of an example composite wing 


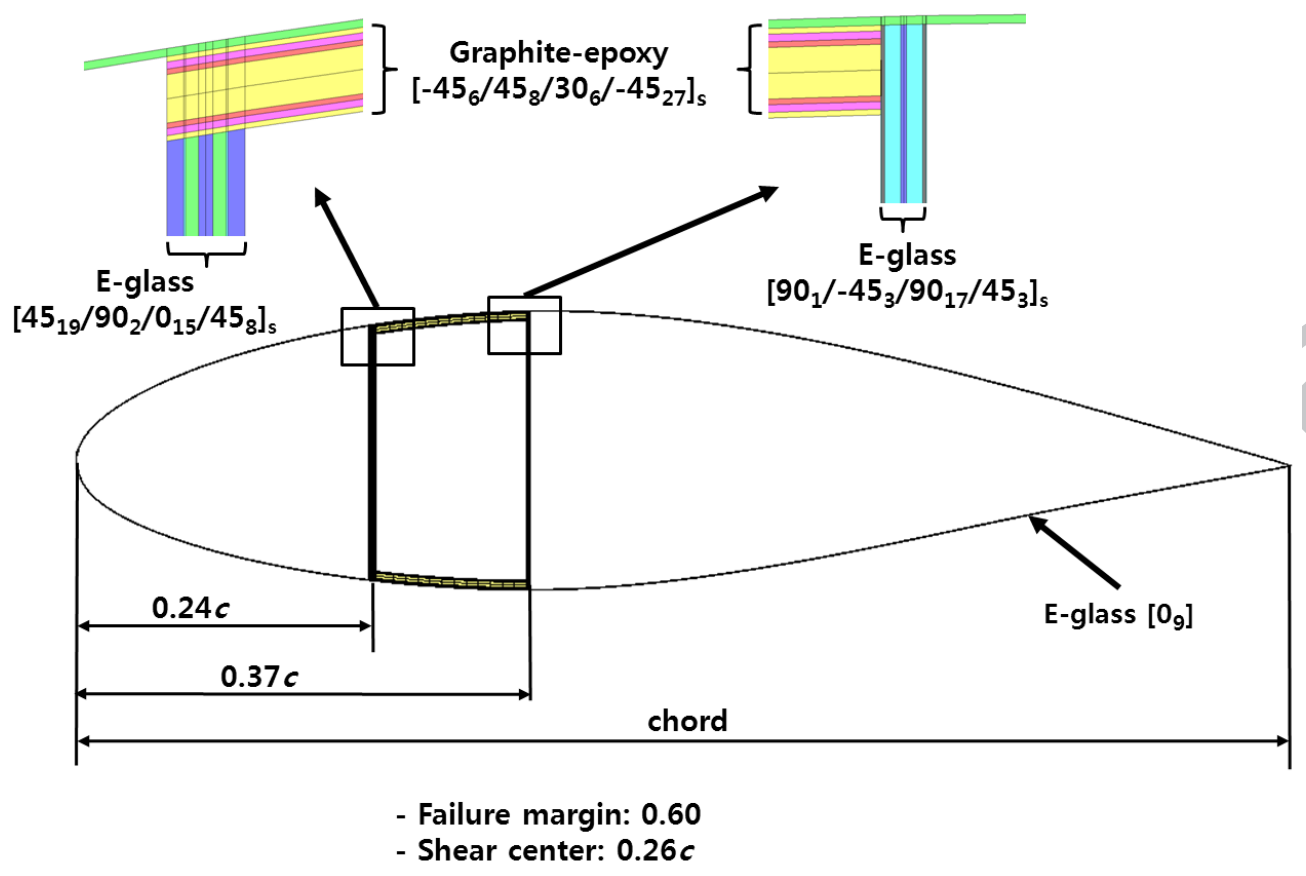

Figure 9. Sketch of the cross sectional design for Case I

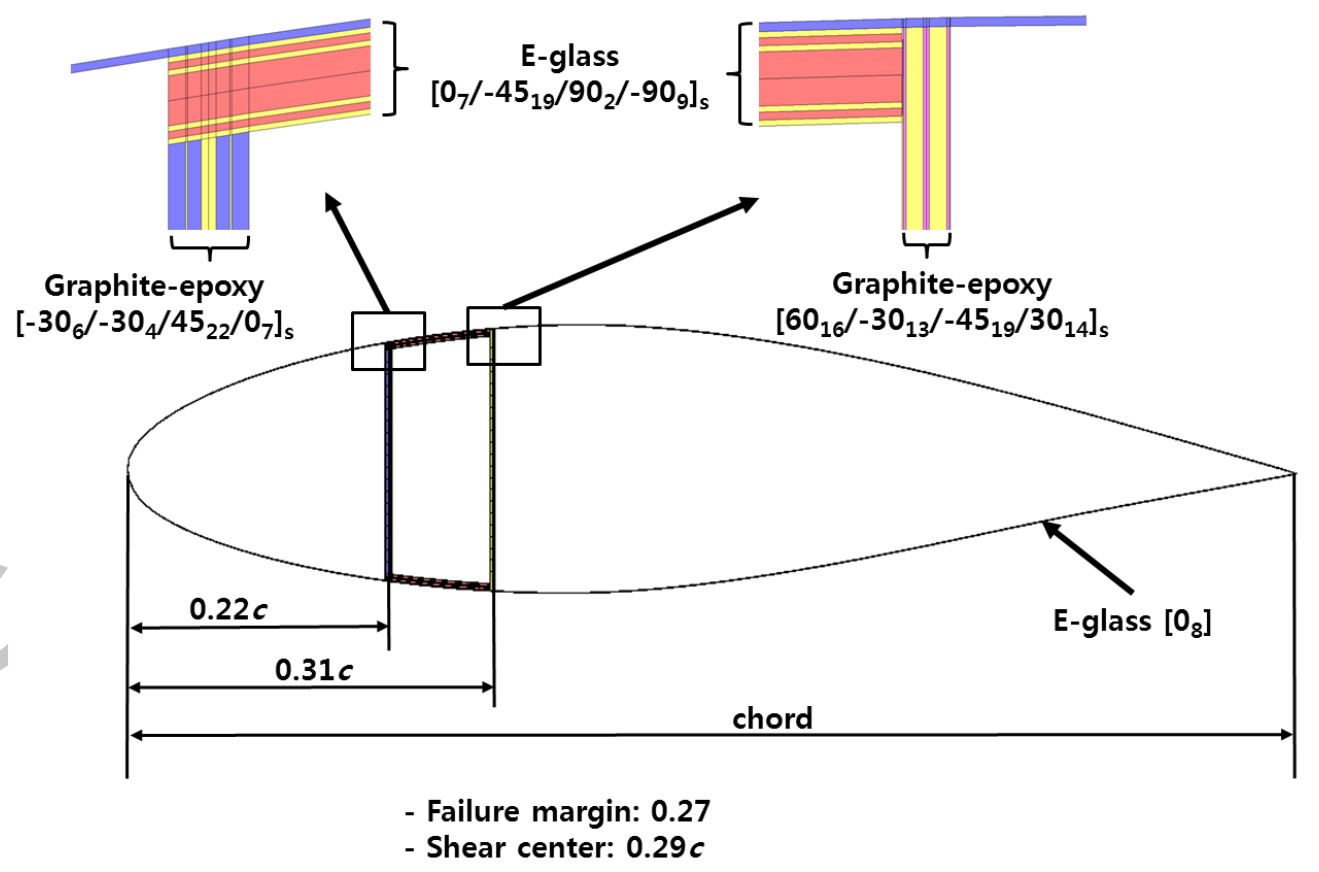

Figure 10. Sketch of the cross sectional design for Case II 


\section{Tables}

Table 1. Design variables used in the present lower-level optimization

\begin{tabular}{clcc}
\hline $\begin{array}{c}\text { Symbol used } \\
\text { in Figure 3 }\end{array}$ & \multicolumn{1}{c}{ Design variables } & $\begin{array}{c}\text { Lower } \\
\text { boundary }\end{array}$ & $\begin{array}{c}\text { Upper } \\
\text { boundary }\end{array}$ \\
\hline A & Rear shear web position & $0.28 c$ & $0.45 c$ \\
B & Front shear web position & $0.15 c$ & $0.27 c$ \\
C & Number of plies for the skin & 1 & 30 \\
D & Number of plies for the spar cap (1) - outmost & 1 & 30 \\
E & Number of plies for spar cap (2) - upper middle & 1 & 30 \\
F & Number of plies for spar cap (3) - lower middle & 1 & 30 \\
G & Number of plies for spar cap (4) - innermost & 1 & 30 \\
H & Number of plies for rear shear web (1) - outmost & 1 & 30 \\
I & Number of plies for rear shear web (2) - upper middle & 1 & 30 \\
J & Number of plies for rear shear web (3) - lower middle & 1 & 30 \\
K & Number of plies for rear shear web (4) - innermost & 1 & 30 \\
L & Number of plies for front shear web (1) - outmost & 1 & 30 \\
M & Number of plies for front shear web (2) - upper middle & 1 & 30 \\
N & Number of plies for front shear web (3) - lower middle & 1 & 90 \\
O & Number of plies for front shear web (4) - innermost & -90 & 90 \\
P & Ply angle for spar cap (1) - outmost & -90 & 90 \\
Q & Ply angle for spar cap (2) - upper middle & -90 & 90 \\
R & Ply angle for spar cap (3) - lower middle & -90 & 90 \\
S & Ply angle for spar cap (4) - innermost & -90 & 90 \\
T & Ply angle for rear shear web (1) - outmost & -90 & 90 \\
U & Ply angle for rear shear web (2) - upper middle & -90 & 90 \\
V & Ply angle for rear shear web (3) - lower middle & -90 & 90 \\
W & Ply angle for rear shear web (4) - innermost & -90 & 90 \\
X & Ply angle for front shear web (1) - outmost & -90 & 90 \\
Y & Ply angle for front shear web (2) - upper middle & -90 & -90 \\
Z & Ply angle for front shear web (3) - lower middle & & 90 \\
AA & Ply angle for front shear web (4) - innermost & 1 & \\
\hline
\end{tabular}

where $c$ is a wing chord length. 
Table 2. Properties of the full-scale XV-15 aircraft

\begin{tabular}{|c|c|}
\hline \multicolumn{2}{|l|}{ Rotor system } \\
\hline Number of blade, $N$ & 3 \\
\hline Radius, $R$ & $3.82 \mathrm{~m}$ \\
\hline Lock number, $\gamma$ & 3.83 \\
\hline Solidity, $\sigma$ & 0.089 \\
\hline \multicolumn{2}{|l|}{ Blade flapping moment of inertia, $I_{b}$} \\
\hline \multicolumn{2}{|l|}{ Blade pitch-flap coupling, $K_{p f}^{*}$} \\
\hline \multicolumn{2}{|l|}{ Rotational speed, $\Omega$} \\
\hline \multicolumn{2}{|l|}{ Lift curve slop, $c_{l_{\alpha}}$} \\
\hline \multicolumn{2}{|l|}{ Wing } \\
\hline Airfoil & NACA 64A223 \\
\hline Semispan, $y_{w_{\text {tip }}}$ & $5.09 \mathrm{~m}$ \\
\hline Chord, $c$ & $1.58 \mathrm{~m}$ \\
\hline Wing mass per length, $m_{w}$ & $32.51 \mathrm{~kg} / \mathrm{m}$ \\
\hline Mast height, $h_{m}$ & $1.31 \mathrm{~m}$ \\
\hline Mass moment of inertia in bending direction, $I_{q_{w}}^{*}$ & $4.03\left(858.39 \mathrm{kgm}^{2}\right)$ \\
\hline Vertical bending stiffness, $K_{q_{1}}^{*}$ & $18.72\left(9.20 \times 10^{6} \mathrm{~kg} \mathrm{~m}^{2} / \mathrm{sec}^{2}\right)$ \\
\hline Chordwise bending stiffness, $K_{q_{2}}^{*}$ & $50.70\left(2.50 \times 10^{7} \mathrm{~kg} \mathrm{~m}^{2} / \mathrm{sec}^{2}\right)$ \\
\hline Torsional stiffness, $K_{p}^{*}$ & $3.595\left(1.77 \times 10^{6} \mathrm{~kg} \mathrm{~m}^{2} / \mathrm{sec}^{2}\right)$ \\
\hline
\end{tabular}


Table 3. Initial value and upper/lower boundaries of the design points Coded values

Physical values

\begin{tabular}{lcc}
\hline$x_{1 \text { upper }}\left(K_{p f \text { upper }}\right)$ & $\sqrt{5}$ & 0 \\
$x_{1 \text { initial }}\left(K_{p f \text { initial }}\right)$ & 0 & -0.0436 \\
$x_{1 \text { lower }}\left(K_{p f \text { lower }}\right)$ & $-\sqrt{5}$ & -0.0875 \\
\hline$x_{2_{\text {upper }}\left(I_{q_{w} \text { upper }}^{*}\right)}$ & $\sqrt{5}$ & 5.3075 \\
$x_{2_{\text {initial }}\left(I_{q_{w} \text { initial }}^{*}\right)}$ & 0 & 4.0300 \\
$x_{2_{\text {lower }}\left(I_{q_{w} \text { lower }}^{*}\right)}$ & $-\sqrt{5}$ & 3.0225 \\
\hline$x_{3 \text { upper }}\left(K_{q 1 \text { upper }}^{*}\right)$ & $\sqrt{5}$ & 23.3995 \\
$x_{3 \text { initial }}\left(K_{q 1 \text { initial }}^{*}\right)$ & 0 & 18.7196 \\
$x_{3 \text { lower }}\left(K_{q 1 \text { lower }}^{*}\right)$ & $-\sqrt{5}$ & 14.0397 \\
\hline$x_{4 \text { upper }}\left(K_{q 2 \text { upper }}^{*}\right)$ & $\sqrt{5}$ & 63.3818 \\
$x_{4 \text { initial }}\left(K_{q 2 \text { initial }}^{*}\right)$ & 0 & 50.7054 \\
$x_{4 \text { lower }}\left(K_{q 2 \text { lower }}^{*}\right)$ & $-\sqrt{5}$ & 38.0290 \\
\hline$x_{5 \text { upper }}\left(K_{p \text { upper }}^{*}\right)$ & $\sqrt{5}$ & 4.4955 \\
$x_{5 \text { initial }}\left(K_{p \text { initial }}^{*}\right)$ & 0 & 3.5964 \\
$x_{5 \text { lower }}\left(K_{p \text { lower }}^{*}\right)$ & $-\sqrt{5}$ & 2.6973 \\
\hline & &
\end{tabular}


Table 4. Central composite design points for creating response surface

\begin{tabular}{|c|c|c|c|c|c|c|c|c|c|c|}
\hline No. & $\begin{array}{c}x_{1} \\
\text { Coded } \\
\text { value }\end{array}$ & $\begin{array}{c}x_{2} \\
\text { Coded } \\
\text { value }\end{array}$ & $\begin{array}{c}x_{3} \\
\text { Coded } \\
\text { value }\end{array}$ & $\begin{array}{c}x_{4} \\
\text { Coded } \\
\text { value }\end{array}$ & $\begin{array}{c}\quad x_{5} \\
\text { Coded } \\
\text { value }\end{array}$ & $\begin{array}{c}x_{1} \\
\text { Physical } \\
\text { value }\end{array}$ & $\begin{array}{c}x_{2} \\
\text { Physical } \\
\text { value }\end{array}$ & $\begin{array}{c}\quad x_{3} \\
\text { Physical } \\
\text { value }\end{array}$ & $\begin{array}{c}x_{4} \\
\text { Physical } \\
\text { value }\end{array}$ & $\begin{array}{c}x_{5} \\
\text { Physical } \\
\text { value }\end{array}$ \\
\hline 1 & 0 & 0 & 0 & 0 & 0 & -0.0436 & 4.0300 & 18.7196 & 50.7054 & 3.5964 \\
\hline 2 & 1 & 1 & 1 & 1 & 1 & -0.0241 & 4.4806 & 20.8125 & 56.3744 & 3.9985 \\
\hline 3 & 1 & 1 & 1 & 1 & -1 & -0.0241 & 4.4806 & 20.8125 & 56.3744 & 3.1943 \\
\hline 4 & 1 & 1 & 1 & -1 & 1 & -0.0241 & 4.4806 & 20.8125 & 45.0364 & 3.9985 \\
\hline 5 & 1 & 1 & -1 & 1 & 1 & -0.0241 & 4.4806 & 16.6267 & 56.3744 & 3.9985 \\
\hline 6 & 1 & -1 & 1 & 1 & 1 & -0.0241 & 3.5794 & 20.8125 & 56.3744 & 3.9985 \\
\hline 7 & -1 & 1 & 1 & 1 & 1 & -0.0631 & 4.4806 & 20.8125 & 56.3744 & 3.9985 \\
\hline 8 & -1 & -1 & 1 & 1 & 1 & -0.0631 & 3.5794 & 20.8125 & 56.3744 & 3.9985 \\
\hline 9 & -1 & 1 & -1 & 1 & 1 & -0.0631 & 4.4806 & 16.6267 & 56.3744 & 3.9985 \\
\hline 10 & -1 & 1 & 1 & -1 & 1 & -0.0631 & 4.4806 & 20.8125 & 45.0364 & 3.9985 \\
\hline 11 & -1 & 1 & 1 & 1 & -1 & -0.0631 & 4.4806 & 20.8125 & 56.3744 & 3.1943 \\
\hline 12 & -1 & 1 & 1 & -1 & -1 & -0.0631 & 4.4806 & 20.8125 & 45.0364 & 3.1943 \\
\hline 13 & -1 & 1 & -1 & 1 & -1 & -0.0631 & 4.4806 & 16.6267 & 56.3744 & 3.1943 \\
\hline 14 & -1 & -1 & 1 & 1 & -1 & -0.0631 & 3.5794 & 20.8125 & 56.3744 & 3.1943 \\
\hline 15 & -1 & -1 & -1 & 1 & -1 & -0.0631 & 3.5794 & 16.6267 & 56.3744 & 3.1943 \\
\hline 16 & -1 & -1 & 1 & -1 & -1 & -0.0631 & 3.5794 & 20.8125 & 45.0364 & 3.1943 \\
\hline 17 & -1 & -1 & -1 & -1 & -1 & -0.0631 & 3.5794 & 16.6267 & 45.0364 & 3.1943 \\
\hline 18 & $\alpha$ & 0 & 0 & 0 & 0 & 0 & 4.0300 & 18.7196 & 50.7054 & 3.5964 \\
\hline 19 & $-\alpha$ & 0 & 0 & 0 & 0 & -0.0875 & 4.0300 & 18.7196 & 50.7054 & 3.5964 \\
\hline 20 & 0 & $\alpha$ & 0 & 0 & 0 & -0.0436 & 5.3075 & 18.7196 & 50.7054 & 3.5964 \\
\hline 21 & 0 & $-\alpha$ & 0 & 0 & 0 & -0.0436 & 3.0225 & 18.7196 & 50.7054 & 3.5964 \\
\hline 22 & 0 & 0 & $\alpha$ & 0 & 0 & -0.0436 & 4.0300 & 23.3995 & 50.7054 & 3.5964 \\
\hline 23 & 0 & 0 & & 0 & 0 & -0.0436 & 4.0300 & 14.0397 & 50.7054 & 3.5964 \\
\hline 24 & 0 & 0 & 0 & $\alpha$ & 0 & -0.0436 & 4.0300 & 18.7196 & 63.3818 & 3.5964 \\
\hline 25 & 0 & 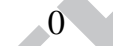 & 0 & $-\alpha$ & 0 & -0.0436 & 4.0300 & 18.7196 & 38.0290 & 3.5964 \\
\hline 26 & 0 & 0 & 0 & 0 & $\alpha$ & -0.0436 & 4.0300 & 18.7196 & 50.7054 & 4.4955 \\
\hline 27 & 0 & 0 & 0 & 0 & $-\alpha$ & -0.0436 & 4.0300 & 18.7196 & 50.7054 & 2.6973 \\
\hline
\end{tabular}


Table 5. Comparisons of the responses obtained between RSM prediction and the aeroelastic analysis

\begin{tabular}{cccc}
\hline No. & $f($ RSM $)$ & $f$ (Analysis) & Difference $(\%)$ \\
\hline 1 & 361.2 & 361.2 & 0.00 \\
2 & 360.8 & 360.1 & 0.18 \\
3 & 354.9 & 354.8 & 0.04 \\
4 & 357.7 & 359.1 & -0.38 \\
5 & 361.9 & 360.1 & 0.50 \\
6 & 360.3 & 360.1 & 0.04 \\
7 & 364.1 & 365.5 & -0.36 \\
8 & 366.9 & 365.5 & 0.39 \\
9 & 371.2 & 369.7 & 0.39 \\
10 & 361.6 & 360.1 & 0.40 \\
11 & 352.0 & 350.5 & 0.42 \\
12 & 346.2 & 346.3 & -0.01 \\
13 & 354.8 & 354.8 & -0.01 \\
14 & 350.5 & 350.5 & -0.01 \\
15 & 356.3 & 354.8 & 0.42 \\
16 & 344.6 & 346.3 & -0.48 \\
17 & 351.2 & 350.5 & 0.19 \\
18 & 342.2 & 342.0 & 0.05 \\
19 & 353.4 & 354.8 & -0.40 \\
20 & 360.1 & 361.2 & -0.37 \\
21 & 361.0 & 361.2 & -0.04 \\
22 & 357.3 & 356.9 & 0.11 \\
23 & 366.0 & 367.6 & -0.44 \\
24 & 363.0 & 365.5 & -0.67 \\
25 & 353.9 & 352.7 & 0.34 \\
26 & 373.9 & 375.1 & -0.30 \\
27 & 340.8 & 340.9 & -0.04 \\
\hline
\end{tabular}

Table 6. Results of the upper-level optimization upon XV-15 aircraft

\begin{tabular}{lll}
\hline Design variables & Baseline & Optimum \\
\hline Pitch-flap coupling $\left(K_{p f}^{*}\right)$ & -0.268 & -0.0837 \\
Wing bending generalized mass $\left(I_{q_{w}^{*}}^{*}\right)$ & 4.0300 & 3.0223 \\
Vertical bending stiffness $\left(K_{q 1}^{*}\right)$ & 18.7196 & 14.0397 \\
Chordwise bending stiffness $\left(K_{q 2}^{*}\right)$ & 50.7054 & 48.5927 \\
Torsion stiffness $\left(K_{p}^{*}\right)$ & 3.5964 & 4.4955 \\
\hline
\end{tabular}


Table 7. Results of the whirl flutter speed for the baseline and optimized XV-15 aircraft

\begin{tabular}{ccccc}
\hline & $\begin{array}{c}\text { Normal quasi-steady } \\
\text { model [17] }\end{array}$ & $\begin{array}{c}\text { Greenberg's model } \\
{[17]}\end{array}$ & $\begin{array}{c}\text { Full unsteady model } \\
{[17]}\end{array}$ & $\begin{array}{c}\text { Present upper-level } \\
\text { optimization }\end{array}$ \\
\hline Flutter speed & $162 \mathrm{~m} / \mathrm{sec}$ & $163 \mathrm{~m} / \mathrm{sec}$ & $170 \mathrm{~m} / \mathrm{sec}$ & $192 \mathrm{~m} / \mathrm{sec}$ \\
\hline
\end{tabular}

Table 8. Validation results of the example composite wing

\begin{tabular}{cccc}
\hline Sectional stiffness & Present & $\begin{array}{r}\text { Two-cell thin-walled } \\
\text { beam section analysis } \\
{[33]}\end{array}$ & Difference, $\%$ \\
\hline$E A(N)$ & $4.89 \times 10^{7}$ & $4.89 \times 10^{7}$ & 0 \\
$G J\left(N-m^{2}\right)$ & $3.55 \times 10^{5}$ & $3.53 \times 10^{5}$ & 0.56 \\
$E I_{v}\left(N-m^{2}\right)$ & $3.59 \times 10^{5}$ & $3.59 \times 10^{5}$ & 0 \\
$E I_{c}\left(N-m^{2}\right)$ & $1.72 \times 10^{7}$ & $1.73 \times 10^{7}$ & 0.58 \\
\hline Max. strain & Present & Two-cell & Difference, $\%$ \\
$(\mu$ strain) & & & -19.8 \\
\hline Fiber longitudinal direction & 492.2 & 613.715 & -11.3 \\
Transverse direction & 544.5 & 613.715 & -3.5 \\
Shear & -714.7 & -690.239 &
\end{tabular}

Table 9. Internal moments prdicted for XV-15 aircraft wing in a cruise flight

\begin{tabular}{cccc}
\hline $\begin{array}{c}\text { Sensor location in } \\
\text { spanwise direction } \\
(\mathrm{m})\end{array}$ & $\begin{array}{c}\text { Torsion } \\
(\mathrm{N}-\mathrm{m})\end{array}$ & $\begin{array}{c}\text { Vertical bending } \\
\text { moment }(\mathrm{N}-\mathrm{m})\end{array}$ & $\begin{array}{c}\text { Chordwise bending } \\
\text { moment }(\mathrm{N}-\mathrm{m})\end{array}$ \\
\hline 0 & -360 & $-39,643$ & $-13,285$ \\
0.61 & -360 & 20,309 & $-13,202$ \\
1.22 & -360 & 3,190 & $-12,673$ \\
1.83 & -360 & $-11,714$ & $-11,699$ \\
2.44 & -360 & $-24,404$ & $-10,279$ \\
3.05 & -360 & $-34,879$ & $-8,413$ \\
3.66 & -360 & $-43,139$ & $-6,102$ \\
4.27 & -360 & $-49,185$ & $-3,345$ \\
4.88 & -360 & $-53,016$ & -143 \\
\hline
\end{tabular}


Table 10. Material properties and maximum allowable strain values of E-glass 120 and T300/5280 Graphite-epoxy

\begin{tabular}{ccc}
\hline Material property & E-glass & Graphite-epoxy \\
\hline$E_{11}$ & $14,800 \mathrm{MPa}$ & $181,000 \mathrm{MPa}$ \\
$E_{22}$ & $13,600 \mathrm{MPa}$ & $10,300 \mathrm{MPa}$ \\
$G_{12}$ & $1,900 \mathrm{MPa}$ & $7,17 \mathrm{GPa}$ \\
$v_{12}$ & 0.19 & 0.28 \\
\hline Maximum strain values & E-glass & Graphite-epoxy \\
\hline Longitudinal tensile & $14,286 \mu$ strain & $8,300 \mu$ strain \\
Longitudinal compression & $-14,286 \mu$ strain & $390 \mu$ strain \\
Transverse tensile & $15,857 \mu$ strain & $8,400 \mu$ strain \\
Transverse compression & $-15,857 \mu$ strain & $240 \mu$ strain \\
Shear & $22,167 \mu$ strain & $9,500 \mu$ strain \\
\hline
\end{tabular}

Table 11. Comparison between the target and optimized values in Case I and II

\begin{tabular}{cccccc}
\hline Objetive function & Target & Case I & Difference (\%) & Case II & Difference (\%) \\
\hline$I_{q_{w}}^{*}$ & 3.0223 & 3.0135 & -0.29 & 3.021 & -0.04 \\
$\left(\mathrm{kgm}^{2}\right)$ & $(643.75)$ & $(641.88)$ & & $(643.47)$ & \\
$K_{q 1}^{*}$ & 14.0397 & 14.0257 & & 13.9119 & -0.91 \\
$(\mathrm{Nm})$ & $\left(6.8902 \times 10^{6}\right)$ & $\left(6.8830 \times 10^{6}\right)$ & -0.10 & $\left(6.8274 \times 10^{6}\right)$ & \\
$K_{q 2}^{*}$ & 48.5927 & 49.3070 & & 48.9766 & 0.79 \\
$(\mathrm{Nm})$ & $\left(2.3846 \times 10^{7}\right)$ & $\left(2.4197 \times 10^{7}\right)$ & 1.47 & $\left(2.4035 \times 10^{7}\right)$ & \\
$K_{p}^{*}$ & 4.4955 & 4.4951 & & 4.5076 & 0.27 \\
$($ Nm $)$ & $\left(2.2084 \times 10^{6}\right)$ & $\left(2.2082 \times 10^{6}\right)$ & -0.01 & $\left(2.2143 \times 10^{6}\right)$ & \\
Failure Margin & & 0.603 & - & 0.266 & - \\
\hline
\end{tabular}

where the values in the brackets illustrate the dimensional quantities. 